AperTO - Archivio Istituzionale Open Access dell'Università di Torino

\title{
Arbuscular mycorrhizal fungal diversity in the Tuber melanosporum brûlé
}

\section{This is the author's manuscript}

Original Citation:

Availability:

This version is available http://hdl.handle.net/2318/1508663

since 2015-12-18T10:05:29Z

Published version:

DOI:10.1016/j.funbio.2015.02.003

Terms of use:

Open Access

Anyone can freely access the full text of works made available as "Open Access". Works made available under a Creative Commons license can be used according to the terms and conditions of said license. Use of all other works requires consent of the right holder (author or publisher) if not exempted from copyright protection by the applicable law. 


\section{(3) \\ UNIVERSITÀ DEGLI STUDI DI TORINO}

This is an author version of the contribution published on:

Questa è la versione dell'autore dell'opera:

[Fungal Biology, 2015, DOI: 10.1016/j.funbio.2015.02.003]

The definitive version is available at:

La versione definitiva è disponibile alla URL:

[http://www.sciencedirect.com/science/article/pii/S1878614615000215] 


\section{Arbuscular mycorrhizal fungal diversity in the Tuber melanosporum brûlé}

Antonietta Mello, Erica Lumini, Chiara Napoli, Valeria Bianciotto, Paola Bonfante

\section{Abstract}

The development of the fruiting body (truffle) of the ectomycorrhizal fungus Tuber melanosporum is associated with the production of an area (commonly referred to with the French word brûlé) around its symbiotic plant that has scanty vegetation. As truffles produce metabolites that can mediate fungal-plant interactions, the authors wondered whether the brûlé could affect the arbuscular mycorrhizal fungi (AMF) that colonize the patchy herbaceous plants inside the brûlé. A morphological evaluation of the roots of plants collected in 2009 from a T. melanosporum/Quercus pubescens brûlé in France has shown that the herbaceous plants are colonized by AMF to a great extent. An analysis of the $18 \mathrm{~S}$ rRNA sequences obtained from roots and soil inside the brûle has shown that the AMF community structure seemed to be affected in the soil inside the brûlé, where less richness was observed compared to outside the brûlé.

Keywords

AMF; Biodiversity; Ectomycorrhiza; Herbaceous plants; Soil; Truffle 
Truffles are ectomycorrhizal (ECM) fungi that produce hypogeous fruiting bodies, belonging to the Tuber genus (Ascomycota, Pezizales). The development of mycorrhizal symbiosis in some Tuber species is associated with the production of a 'burnt' area (commonly referred to with the French word brûlé) around their symbiotic plants. This brûlé is usually circular, is characterized by scanty vegetation and is typical of Tuber melanosporum Vittad. and T. aestivum Vittad. ( Pacioni 1991). Splivallo et al. (2007) have demonstrated the inhibitory effect of truffle volatiles on the development of the nonhost plant Arabidopsis thaliana in laboratory conditions, and have indicated that fungal volatiles are molecules that can mediate fungal-plant interactions, thus raising questions about their role in the origin of the brûlé. In addition, truffle mycelia produce ethylene and indole-3-acetic acid (IAA), which, in large quantities, might act as herbicides and thus explain the formation of the brûlé ( Splivallo et al. 2011). What actually causes the brûle is not known precisely, although some studies have recently reported its impact on the microorganisms that live inside this area ( Napoli et al., 2010 and Mello et al., 2013; see below).

Tuber melanosporum grows in symbiosis with several oak species and hazelnut trees in France, Italy, and the Iberian Peninsula, and has also been introduced successfully, from these Mediterranean areas, to New Zealand, Australia, Israel, and North America ( Mello et al. 2006). Previous work on the composition of fungal communities inside and outside of the $T$. melanosporum brûlés revealed clear differences between the fungal communities, as well as a lower fungal biodiversity inside the brûlé ( Napoli et al. 2010). Tuber melanosporum was found to be the dominant fungus within the brûlé, where Basidiomycota ectomycorrhizal fungi decreased, indicating a competitive effect of $T$. melanosporum with the other ectomycorrhizal fungi. Mello et al. (2011) have confirmed this fungal dominance by means of 454pyrosequencing data of the same soils, while Streiblová et al. (2012) suggested that truffles adopt an efficient survival strategy by spreading their metabolites, which are regarded as having allelopathic effects on the herbaceous plants and the microorganisms in the rhizosphere. As ectomycorrhizal fungi interact with soil communities to establish a multi-trophic ectomycorrhizal complex ( Frey-Klett et al. 2007), Mello et al. (2013) compared the bacterial communities between the interior and exterior zones of the brûlé to investigate the potential effects of $T$. melanosporum growth and metabolites on such communities. All the samples were analysed by means of Denaturant Gradient Gel Electrophoresis (DGGE), and one truffleground was also analyzed using phylogenetic microarrays. The DGGE profiles showed differences in the bacterial community composition, and the microarrays revealed a few differences in the relative richness between the interior and exterior zones of the brûlé, as well as differences in the relative abundance of several taxa. Firmicutes (e.g., Bacillus), several genera of Actinobacteria, and a few Cyanobacteria were found more frequently inside the brûlé than outside, whereas Pseudomonas and several genera from the Flavobacteriaceae family were more abundant outside the brûlé. These findings have demonstrated that not only are fungal communities affected by $T$. melanosporum, but also other microorganisms. Among the various plant microbiota, another important microbial group that belongs to Phylum Glomeromycota ( Smith \& Read 2008), and forms a mutualistic symbiosis with most land plants, is that of arbuscular mycorrhizal fungi (AMF). Since most herbaceous plants are colonized by these fungi, and the existence of the brûlé is associated with scanty vegetation and changes in fungal and bacterial communities, it is possible to imagine that the brûle could have an effect on the AMF that colonize the vegetation in the brûlé. The aim of this work was therefore to elucidate whether the scanty plant coverage around the T. melanosporum host tree reflects a change in AMF biodiversity, compared to the area outside, where the vegetation coverage is regular. As a first step of this investigation, a search was made to establish the 
presence of AM fungi in the roots of the patchy herbaceous plants in the brûlé. In the subsequent step, the AM fungal communities inside and outside the brûle were investigated in both the soil and in the herbaceous roots. Samples were collected in a productive truffle-ground in Cahors, France, that had previously been investigated for fungal and bacterial analyses, and the $18 \mathrm{~S}$ rDNA region was processed through molecular cloning.

\section{Material and methods}

\section{Site description}

The sampling area is a natural and productive Tuber melanosporum truffle ground situated in La Bigouse, and it belongs to La Station de la trufficulture de Cahors-Le Montat (Station d'expérimentation sur la truffe, Lycée professionnel agricole Lacoste, Le Montat, France). A clear and extensive brûlé was observed in this truffle-ground surrounding the host tree, Quercus pubescens, and was choosen for soil and root sampling. The brûlé has an irregular [half-moon] $5 \mathrm{~m}$ long and $1.5 \mathrm{~m}$ wide shape. The pedological properties have already been described in Napoli et al. (2010). The mean values of the granulometric fraction contents are: $19.3 \%$ clay, $48.6 \%$ silt, and $32.1 \%$ sand. The total $\mathrm{N}$ was $3 \mathrm{~g} \mathrm{~kg}-1$ inside and outside the brûlé, the organic matter was $5.8 \%$ inside the brûlé and $6.8 \%$ outside, while the $\mathrm{pH}$ 8. The herbaceous plants, found inside and outside the brûlé of the selected truffle-ground, were identified as belonging to Achillea, Alyssum, Arenaria, Artemisia, Astragalus, Bromus, Capsella, Cerastium, Cerinte, Clinopodium, Cynodon, Erigeron, Festuca, Gallium, Hieracium, Knautia, Lathyrus, Leucanthemum, Lotus, Myosotis, Plantago, Pimpinella, Poa, Reseda, Salvia, Sedum, Sonchus, Taraxacum, Trifolium, Veronica, Vicia, and Vulpia genera. These plants presented a patchy distribution inside the brûlé but a uniform one outside.

\section{Soil and root sampling}

Six soil cores, three from inside and three from outside the brûlé, were collected in May 2009 at a depth of approximately $10-15 \mathrm{~cm}$. The cores from each area were pooled to form one sample and then passed through a $2 \mathrm{~mm}$ sieve to make them homogeneous. The two samples (one from inside and one from outside the brûlé) were stored at $-80^{\circ} \mathrm{C}$ until they were analysed. In addition to the soil samples, the roots of some Festuca, Myosotis, Plantago, and Bromus plants were collected randomly inside and outside the brûle to investigate the mycotrophic status. Among these roots, Bromus erectus (belonging to the Poaceae family) was selected for a more detailed analysis because it was possible to collect at least four plants around the brule in order to have a representative sample of the plant roots and their coverage. With this aim, the roots of four B. erectus plants were collected both inside and outside the brûlé, and used partly for morphological and partly for molecular analyses. All the plant roots were washed carefully with water to remove soil, then rinsed briefly and dried quickly on paper.

\section{Root morphological analysis}

The root apparatus of Festuca, Myosotis, Plantago, and Bromus plants was stained with $0.1 \%$ cotton blue in lactic acid to investigate their mycotrophic status. Some roots rich in pigments were initially cleaned in $10 \% \mathrm{NaOH}$ at $60^{\circ} \mathrm{C}$ for $30 \mathrm{~min}$. After washing, the roots were cut into fragments of about $1 \mathrm{~cm}$ and 
mounted onto slides for observation under a light microscope. In addition, eight Bromus erectus plants, collected inside and outside the brûlé, were subjected to a quantitative analysis. Eight hundred fragments of B. erectus roots were observed ( 400 from plants collected inside and 400 from plants collected outside the brûlé). The intensity of the fungal colonisation of the root cortex and the presence of arbuscules were determined as described in Trouvelot et al. (1986). These data were statistically analysed by means of the non-parametric Kruskal-Wallis one-way ANOVA test (Systat 10); differences were considered significant when the $P$ value was $<0.05$.

DNA extraction, molecular cloning and sequencing from soil and roots colonised by AMF

The total DNA was extracted from $0.5 \mathrm{~g}$ of each composite soil sample (made up of three cores), as reported in Napoli et al. (2010). Two extractions were made for each sample and were mixed in order to obtain the most representative DNA of the soil sample. Two DNA samples (one from inside the brûle and the other from outside) were amplified separately using two pairs of primers in order to establish taxa coverage: the universal eukaryotic primer NS31 (Simon et al. 1992) in combination with the AMF primer AM1 (Helgason et al. 1998), and the AMF primers AML1/AML2 (Lee et al. 2008). The target region of both these pairs of primers was the $18 \mathrm{~S}$ rDNA region. This marker was chosen due to the low variability of its AMF sequences, compared to the ITS region, which facilitates phylogenetic analyses, and because of the existence of a well populated and open-access database (Öpik et al., 2010 and Krüger et al., 2012). PCR was carried out with both pairs under the same conditions, except for the annealing temperature: a final volume of $25 \mathrm{ul}$, containing approximately $5 \mathrm{ng}$ of DNA template; 20 pmoli of each primer; $0.25 \mathrm{ul} \mathrm{BSA}$ (100x); 2.5 ul 10x buffer; $0.2 \mu \mathrm{M}$ dNTPs and one unit of Red Taq DNA polymerase (Sigma-Aldrich). The cycling parameters were: $94^{\circ} \mathrm{C}$ for $4 \mathrm{~min}$; followed by 30 cycles: $94^{\circ} \mathrm{C}$ for $30^{\prime \prime}, 63^{\circ} \mathrm{C} / 58^{\circ} \mathrm{C}$ for $45^{\prime \prime}, 72^{\circ} \mathrm{C}$ for 45"; and a final extension of $72^{\circ} \mathrm{C}$ for $10 \mathrm{~min}$. The PCR products from the two samples (inside and outside the brûlé) were purified with the QIAquick PCR Purification Kit [Qiagen]. Two libraries were formed for each pair of primers. The PCR products of each pool were ligated into the PGEM-T vector using a PGEM-T vector system (Promega) and Escherichia coli competent cells (XL1 blue). The putative positive transformants from each library were screened utilizing the same pair of primers used to obtain the PCR products, under the previously described conditions. Colonies that showed an insert of the expected size (about $550 \mathrm{bp}$ for NS31/AM1 and about 750 bp for AML1/AML2) were sequenced. A total of 360 clones screened with NS31/AM1 (180 from inside and outside the brûlé, respectively) were sequenced, whereas 190 clones (95 from inside and outside the brûlé, respectively) were sequenced for AML1/AML2. Chimeric sequences, or sequences belonging to other fungal phyla, were removed from the analysis.

The total DNA was extracted in duplicate from about $50 \mathrm{mg}$ of each mycorrhizal Bromus erectus sample (made up of four plants) with the Dneasy Plant Mini kit (Qiagen). PCR was carried out using the AML1/AML2 pair of primers on two samples (inside and outside the brûlé). The cloning procedure was the same as that described for the soil DNA. Ninety-four clones ( 49 from inside and 45 from outside) were sequenced from the root samples. The sequences obtained from the four libraries were then submitted to the Gene bank and their accession numbers are: KM368370 -KM368804. 


\section{Sequence analysis}

Sequence similarity was first determined using the nucleotide BLAST search tool provided by GenBank (http://blast.ncbi.nlm.nih.gov), and then the online database MaarjAM (http://maarjam.botany.ut.ee/) to screen for Glomeromycota diversity. Multiple alignments were generated for each clone library, using the CLUSTALX programme with default parameters (Thompson et al. 1997), and alignments were adjusted manually in Gene-Doc (Nicholas et al. 1997). Distant matrixes were constructed using DNAdist from PHYLIP, version 3.68, (http://evolution.genetics.washington.edu/phylip.html) with default parameters. These pairwise distances were used as input for MOTHUR (Schloss et al. 2009) in order to cluster the sequences into Operational Taxonomic Units (OTUs) of a defined sequence identity. A threshold of $97 \%$ identity, corresponding to 0.03 dissimilarity, was used to define the OTUs. Although this distance cut-off is arbitrary, and can be considered controversial, it was chosen on the basis of previous studies on AMF biodiversity (Lumini et al., 2010 and Borriello et al., 2012). Two reorganizations of the Glomeromycota classification have recently been published (Oehl et al., 2011 and Krüger et al., 2012). In the present study, the nomenclature suggested by Krüger et al. (2012) was adopted, for ease of data handling, in order to identify the sequences through comparisons with the virtual taxa deposited in the MaarjAM database. One sequence was used for each OTU to construct a phylogenetic tree, employing MEGA 4 software with Kimura's two-parameter model and the neighbour-joining algorithm. Clade stability was assessed using bootstrap analysis with a 1000 replicate data set. Twenty-five Glomeromycota sequences were used as reference sequences. All these sequences were chosen from the GenBank collection and indicated with their own accession number in the obtained phylogenetic tree. A sequence of Mortierella verticillata was used as the outgroup, according to Borriello et al., (2012).

\section{Results}

\section{Morphological evaluation of AMF root colonization}

The Festuca, Myosotis, Plantago, and Bromus plants resulted to be colonized by AM fungi. Characteristic AMF structures were observed constantly in the roots from both of the collected areas, thus revealing the presence of AMF both inside and outside the brûlé ( Fig. 1). The quantitative analysis on Bromus erectus roots exhibited a very high degree of AMF colonization, the mean percentage value of the frequency being $94 \%$. No significant difference was observed for the B. erectus colonization inside and outside the brûlé. 


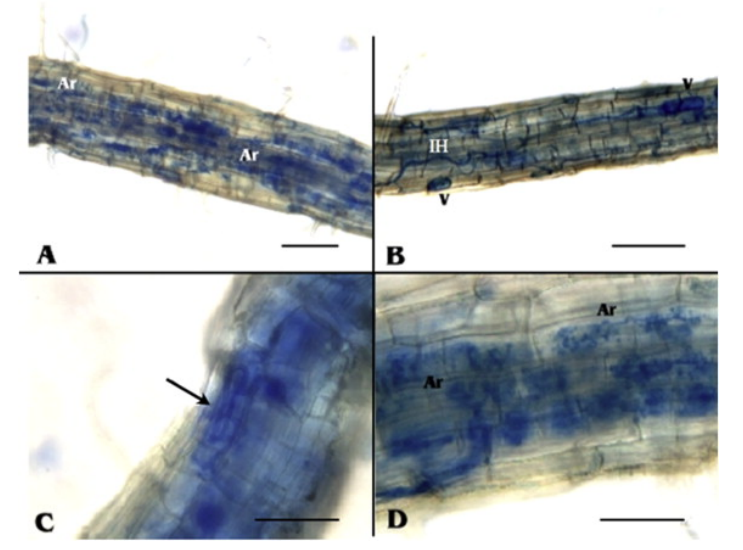

Fig 1. Characteristic arbuscular structures in Bromus erectus roots. (A-C). Bromus erectus roots collected inside the brûlé. Intraradical hyphae $(\mathrm{IH})$, along with intraradical vesicles $(\mathrm{V})$, arbuscules (Ar), and coils (arrow) are shown pervading the root apparatus. D. Bromus erectus roots collected outside the brûlé. Details of intracellular arbuscules (Ar) colonizing large patches of the root cortex. In A and B the bars correspond to $200 \mu \mathrm{m}$ and in $C$ and $D$ to $50 \mu \mathrm{m}$.

\section{AMF assemblage identification in soils and roots}

First, the soil DNA was amplified with the NS31/AM1 pair of primers. Two hundred and twenty-seven Glomeromycota sequences were obtained, 89 from inside and 138 from outside the brûlé, respectively. The sequences grouped into seven OTUs and four singletons for inside as well as for outside the brûlé. The nonparametric richness estimators ACE and Chao1 were calculated to obtain the estimated OTU numbers (Chao et al., 1993 and Chao et al., 2006). They are important to reduce sampling errors and, especially ACE, to weigh rare species, because most common species are easier to identify in every communities. Their values $($ ACE (inside) $=10.2( \pm 1.7)$ and ACE(outside) $=8.7( \pm 1.30)$; Chao1 (inside) $=7.3( \pm 0.9)$ and Chao1 (outside) $=7.5$ ( \pm 1.2 ); $95 \%$ confidence) indicated that the number of expected OTUs outside the brûle was similar to that which was actually observed, whereas the number expected inside the brûlé was slightly different from the number that was actually observed. Specifically the ACE value means that inside the brûle more OTUs could be present. All the sequences, including the singletons which have not been considered in the discussion, showed similarity with the members of Glomerales ( Fig. 2). The most abundant OTU (OTU1a) was present more in the soil outside the brûlé, where it represented $74.6 \%$ of the sequences, and showed similarity with Funelliformis mosseae (VTX00067); the second and third OTUs, in terms of abundance, were instead present more inside the brûlé and showed similarity with Septoglomus sp. (VTX00063) and Glomus sp. (VTX00214), respectively. 


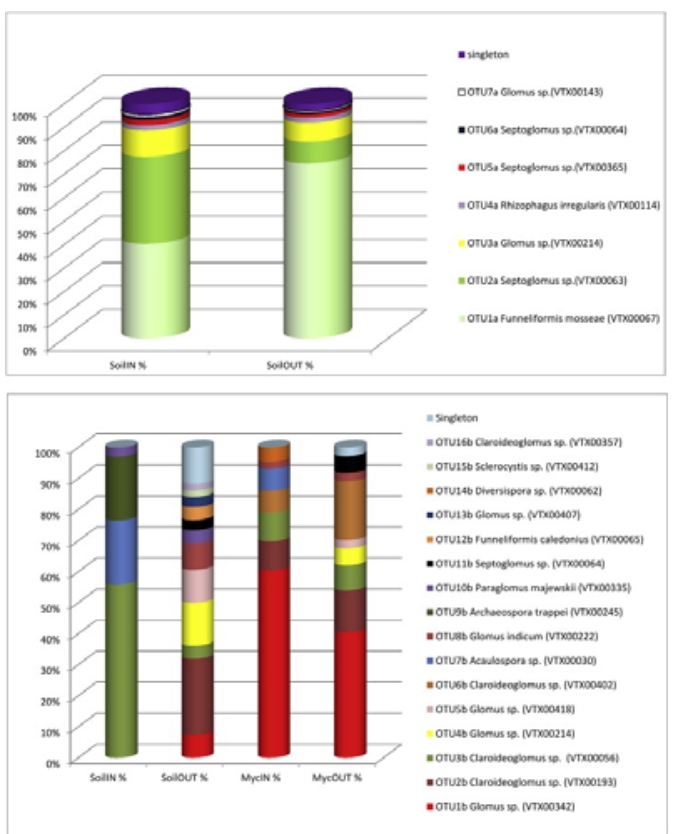

Fig 2. Percentage of OTUa obtained with the NS31/AM1 pair of primers and OTUb obtained with the AML1/AML2 pair of primers from soil and roots collected inside and outside the brûlé (SoilIN, MycIN, SoilOUT, MycOUT). Sequence similarity was determined using the MaarjAM database (http://maarjam.botany.ut.ee/), and, when possible, the genera/species were assigned using the nomenclature of Krüger et al. (2012).

In order to obtain a greater taxa coverage, the same soil DNA was amplified with the AML1/AML2 pair of primers. The DNA from the Bromus erectus roots, was also amplified with these primers. One hundred and twenty-eight Glomeromycota sequences were obtained from the soil, 34 from inside and 94 from outside the brûlé, while 80 Glomeromycota sequences were obtained from the Bromus roots, 43 from inside and 37 from outside. The sequences from both the soil and the roots (208 sequences) were grouped to generate OTUs. The sequences from the soil were grouped into four OTUs for inside the brûlé, and 12 OTUs and 11 singletons for outside, respectively, whereas the sequences from the mycorrhizal roots were grouped into seven OTUs for inside the brûlé, and eight OTUs and one singleton for outside ( Fig. 2). The values of the non-parametric richness estimators relative to the soil (ACE (inside) $=4.5( \pm 2.6)$ and ACE(outside) $=12( \pm 1.2)$; Chao1 (inside) $=4( \pm 0.4)$ and Chao1(outside) $=12( \pm 0))$ indicated that the number of observed OTUs was equal to the expected number, and the estimations relative to the mycorrhizal roots $($ ACE (inside) $=7.4( \pm 1.0)$ and $\mathrm{ACE}$ (outside) $=9.5( \pm 1.3)$; Chao1(inside) $=7( \pm 0.2)$ and Chao1(outside) $=8.3$ (0.9)) were in the range of the observed OTUs. The rarefaction curves, related to the $97 \%$ sequence identity SSU OTUs detected in the two soils, indicate that the sampling was able to identify a large proportion of the soil AMF community diversity, whereas the rarefaction curves relative to the mycorrhizal roots showed a decreasing accumulation rate of OTUs, especially in the roots inside the brûlé, but did not reach the asymptote ( Fig. 3). 


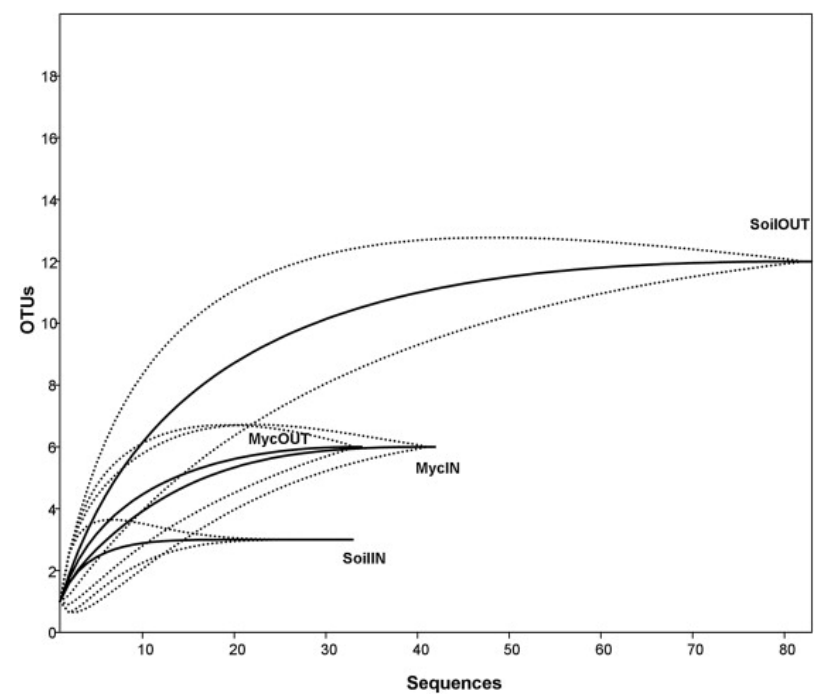

Fig 3. The rarefaction curves for the fungal operational taxonomic units (OTUs) observed in soil and roots inside and outside the brûlé (SoilIN, MycIN, SoilOUT, MycOUT). The dotted lines indicate the upper and lower 95 \%-confidence intervals.

The Shannon-Weaver biodiversity index $\left(\mathrm{H}^{\prime}\right)$ was also calculated to compare the AMF diversity of the two habitats in both the soil and mycorrhizal roots. The values relative to the soil $\left(\mathrm{H}^{\prime}\right.$ (inside) $=1.1$ and $\mathrm{H}^{\prime}$ (outside) $=2.2$ ) and to the mycorrhizal roots $\left(\mathrm{H}^{\prime}(\right.$ inside $)=1.3$ and $\mathrm{H}^{\prime}$ (outside $\left.)=1.7\right)$ both indicated higher biodiversity outside the brûlé.

The sequences showed similarity with members of the Glomus, Sclerocystis/Rhizophagus, Claroideoglomus, Septoglomus, Archaeospora, Acaulospora, Paraglomus, and Diversispora genera. The most abundant OTU (OTU1b) was more present in the mycorrhizal roots (60.5\% inside and $40.5 \%$ outside) than in the soil, where it was only found outside the brûle (7.4\%), and showed similarity with Glomus sp. (VTX00342); the second OTU (OTU2b), in terms of abundance, was present in the roots and the soil outside the brûlé, and showed similarity with Claroideoglomus sp. (VTX00193). Thirteen OTUs were made up of a few sequences and among these, OTU7b included sequences which showed similarity with Acaulospora sp. (VTX00030) and were only present in the roots and soil inside the brûlé. Seven sequences which showed similarity with Archaeospora trappei (VTX00245) were only present in the soil inside the brûlé, whereas five sequences similar to Paraglomus majewskii (VTX00335) were present in the soil both inside and outside the brûlé, but not in the roots. Two sequences showed similarity with Diversispora sp. (VTX0062) and were found in the mycorrhizal roots inside the brûlé.

Once the biodiversity covered by the two pairs of primers had been established, all the sequences were grouped to verify the presence of common OTUs. Only two OTUs were shared: sequences from OTU3a (Glomus sp. VTX00214), which grouped with those of OTU4b (Glomus sp. VTX00214), and sequences from OTU6a (Septoglomus sp. VTX0064), which grouped with those of OTU11b (Septoglomus sp. VTX0064).

In order to verify the position of the AMF phylotypes that have been obtained with both pairs of primers, NS31/AM1 and AML1/AML2, a phylogenetic tree was constructed (Fig. 4). The percentage of each OTU 
over the total number of sequences in the soil and in the mycorrhizal roots is also reported beside the tree. From the combination of the two analyses, it is possible to see that 19 OTUs ( 7 from the amplification with NS31/AM1, and 12 from the amplification with AML1/AML2) out of 23 belong to Glomerales.

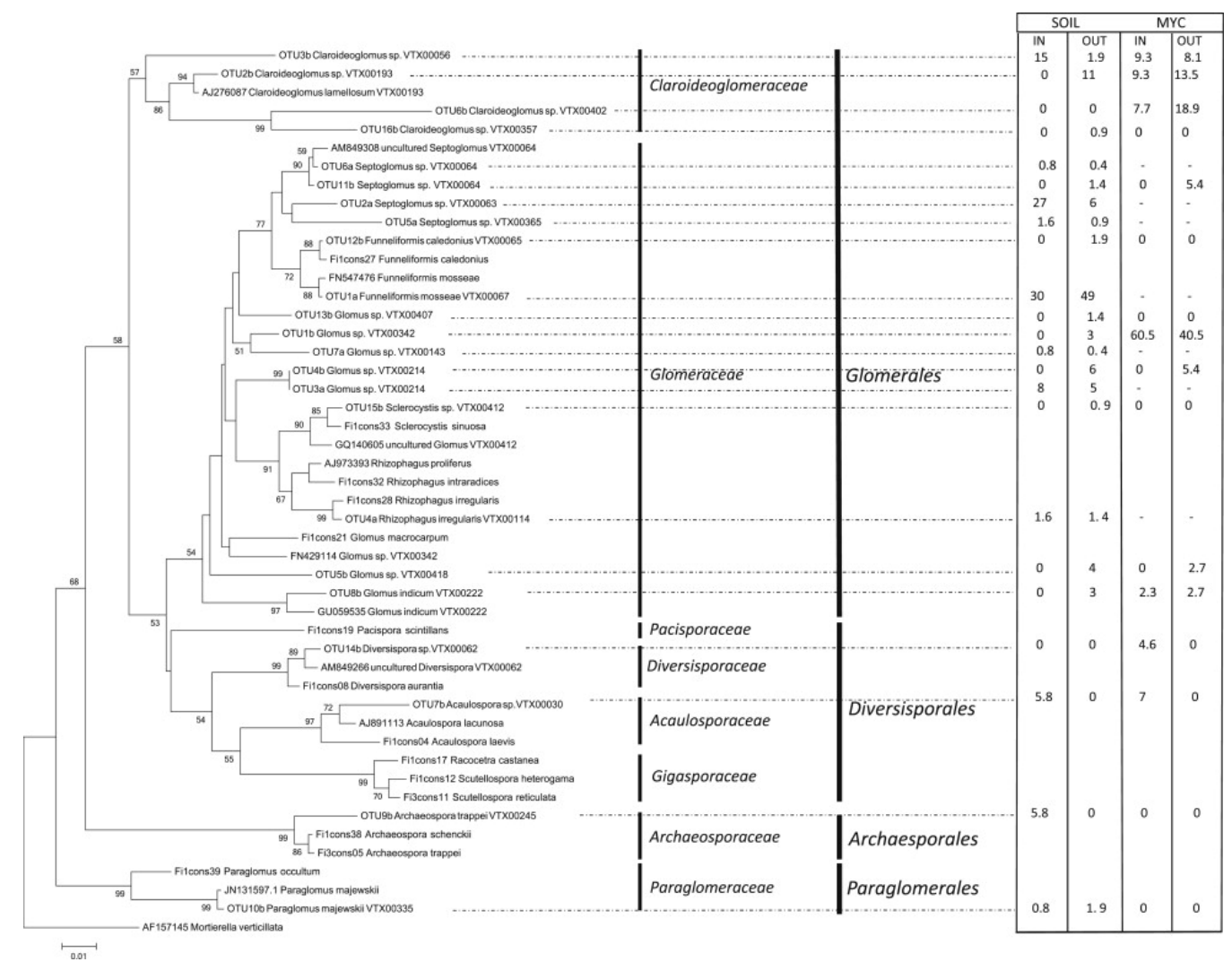

Fig 4. Neighbour joining tree constructed on a 444 bp allignment obtained from a representative sequence for each OTU (OTUa and OTUb from amplification with NS31/AM1 and AML1/AML2, respectively). The percentage of each OTU on the total number of sequences in the soil (119 inside and 207 outside the brûlé, excluding singletons) and in the mycorrhizal roots (43 inside and 37 outside the brûlé) is reported beside the tree.

\section{Discussion}

AMF have been investigated in a multitude of environments, from tropical forests to agro-environments and sand dunes (Turrini and Giovannetti, 2012 and Öpik et al., 2013). However, to the best of the authors' knowledge, AMF biodiversity has never been described in such environments as truffle-grounds in which AMF could interact directly with herbaceous plant roots and indirectly with ectomycorrhizal fungi. However, the colonization of non-host plants by ectomycorrhizal fungi has occasionally been described. Selosse et al. (2004) and Gryndler et al. (2014) have reported an association between these plants and T. aestivum. While the former detected the fungus in orchid roots, the latter measured its abundance in roots of all plants growing in a brûlé and concluded, from a microscopical inspection of the roots, that T. aestivum is located on the root surface. A close correlation between infection in herbaceous plant roots and Tubermelanosporum was observed by Plattner \& Hall (1995), who demonstrated that T. melanosporum caused necrosis in the root cortices of Anthoxanthum odoratum, and Leontodon taraxacoides, thus suggesting that this fungus is pathogenic to the weeds, and in part responsible for the brûlé, thanks to this apparent pathogenic effect and to the production of toxic volatiles. Since the inhibitory effect of T. melanosporum volatiles on herbaceous plants has been widely acknowledged ( Splivallo et al., 
2007, Splivallo et al., 2011 and Streiblova et al., 2012), which would seem to indicate that fungal volatiles can mediate fungal-plant interactions, it is possible to imagine that there could also be an effect of T. melanosporum on the AMF that colonize the patchy vegetation. This work clearly shows, for the first time, that the patchy herbaceous plants around a T. melanosporum host tree are colonized by AMF to a great extent, as are the plants outside the brûlé, where the vegetation coverage is regular. In addition, no necrosis was observed in their root cortices, which would seem to suggest that the plants that survive in the brûlé are the most resistant to allelopathics produced by T. melanosporum, and that AMF heavy colonization of the root volume prevents and/or reduces non-host root colonization by T. melanosporum hyphae. AMF richness does not seem to be affected in the herbaceous plants inside the brûlé, whereas less richness has been observed in the soil compared to outside the brûlé. Members of Diversispora, Acaulospora, and Archaeospora are only found in the brûlé, either in roots or soil, suggesting that this habitat exerts an impact on certain AMF taxa. Whether this situation reflects the effects of T. melanosporum or the effects of local soil nutrients and/or differences in plant communities between plants inside and outside the brûlé cannot be established because a detailed analysis of the nutrients, especially $\mathrm{NO}, \mathrm{NH} 4, \mathrm{P}$ and of the plant communities has not been conducted. It is possible that the changes in abundance and richness of the soil bacteria observed by Mello et al. (2013) induced a flux in soil nitrogen (and possibly carbon) which, in turn, may have influenced the AMF community. In addition, different plant communities (in terms of frequency of species, coverage) inside and outside the brûlé can also promote differences in nutrient cycling and modify local soil nutrient concentrations ( Sigüenza et al. 2006).

Two pairs of primers were used to obtain a broader biodiversity. While the NS31/AM1 pair of primers only captured members of the Glomerales in the truffle-ground, AML1/AML2 was also able to find members of Archaeosporales, Paraglomerales, and Diversisporales genera. Interestingly, only two OTUs were shared: one comprising sequences showing similarity with Glomus sp. (VTX00214), and the other with Septoglomus sp. (VTX00064). This result would seem to indicate that the two pairs of primers cover different taxa, and it offers an indication of the AMF community that lives in a truffle-ground, but it also reveals, as recently pointed out by Kohout et al. (2014), that it is difficult to amplify AMF communities with the common primer pair and that bias appears. In spite of this, discrepancy was here observed between the number of clones that were sequenced and that of the effective Glomeromycota sequences that were obtained, irrespectively of what pair of primers was used. This was more evident inside the brûlé, where there was a high number of no-AMF organisms. The preferential amplification could depend on the amount of colonization ( Dohuan et al. 2005). The larger percentage of non-AMF sequences in the samples inside the brûlé could indicate a minor presence of AMF inside the brûlé than outside (in the absence of a quantitative approach, this eventuality cannot be excluded). This could, in turn, be explained by the characteristic low number of herbaceous plants in the brûlé. In addition, the Shannon-Weaver biodiversity index that was calculated on the basis of sequences produced by the AML1/AML2 pair indicated a lower richness of AMF inside the brûlé. The fact that the number of observed OTUs was equal to the number that was estimated, together with the saturation of richness shown by the rarefaction curves, indicate good sampling efficiency and give robustness to this result.

AMF belonging to Glomerales resulted to be the dominant fungi among the Glomeromycota both inside and outside the brûlé, as reported in several habitats ( Opik et al. 2010). Two of the reasons are that members of this order have good plasticity, due to their great ability to redistribute resources in the 
mycelial network through an anastomosis process ( Giovannetti et al. 1999) and that they have high sporulation rates (Oehl et al. 2003). All the families that are present outside the brûlé are also present inside. Among the taxa (occurring in $>2.5 \%$ of all samples) that are clearly present in the roots or soil outside the brulé, only Glomus sp. VTX00418 is absent in both the roots and soil inside the brulé. Since Glomerales is the largest order of Glomeromycota and comprises functional divergence taxa, the presence/absence of a virtual taxa, and therefore of a specific trait is not strange.

Comparisons between the AMF communities in the soil and in the roots have shown that, in general, not all the OTUs from the roots were represented in the soil and vice versa. Moreover, while the number of OTUs from the roots outside the brûlé was lower than the number from the corresponding soil, that of the OTUs from the roots inside the brûle was instead higher than the number of OTUs from this soil. These results mean that the soil outside maintains a higher AMF biodiversity than the roots, as expected, and that the soil inside the brûlé presents an unusual trend. Only two phylotypes, Acaulospora sp. (VTX00030), and Claroideoglomus sp. (VTX00056), are shared between the soil and roots inside the brûlé, while seven Septoglomus sp. (VTX00064), Glomus indicum (VTX00222), Glomus sp. (VTX00418), Glomus sp. (VTX00214), Claroideoglomus sp. (VTX00193), Claroideoglomus sp. (VTX00056), and Glomus sp. (VTX00342) - are shared between the soil and roots outside the brûlé. Since it is known that Acaulospora spp. are more resistent to biotic and abiotic stresses ( Hart and Reader, 2002 and Maherali and Klironomos, 2007), the finding of Acaulospora sp. (VTX00030) only inside the brûlé cannot be considered unusual, given the particular nature of the brûlé ecosystem. As this niche is very poor in vegetation, root exudates other than those from the T. melanosporum host tree, Quercus pubescens, can be expected to be less abundant than those outside the brûlé, where rich vegetation completely covers the soil. In such a system, the patchy herbaceous plants represent 'nutrient islands' that are easily colonised by AMF, such as the Acaulosporaceae that live preferentially in more stressfull environments. Their presence in the May samplings can be explained by the preferential early season activity of this family ( Hijri et al. 2006). On the other hand, the finding of Archaeospora trappei (VTX00245) in the soil was not expected, since Archaeospora species are not found easily in either soil or in field roots ( Hijri et al. 2006), although more sequences belonging to Archaeospora have recently been discovered by means of next generation sequencing ( Lumini et al., 2010 and Öpik et al., 2010).

\section{Conclusions}

The present results offer a first glimpse into the AMF communities that thrive in a Tubermelanosporum brûlé. AMF are able to colonize the patchy herbaceous plants inhabiting the brûlé to a great extent. Among the Glomeromycota, Glomerales resulted to be the dominant fungi both inside and outside the brûlé, as has already been reported for several other habitats. AMF richness does not seem to be affected in the patchy herbaceous plants inside the brûlé, where they represent 'nutrient islands' that are easily colonised by AMF. Members of Diversispora, Acaulospora, and Archaeospora are only found in the brûlé, either in roots or soil, and less AMF richness has been observed in the soil, thus suggesting that the brûle exerts a selective pressure on certain AMF taxa. It has not been established whether this situation reflects the effects of T. melanosporum or the effects of other factors. However, the brûlé clearly reflects changes in the AMF community structure. A more conclusive understanding of AMF diversity in this peculiar ecological niche will require additional investigations on the different development stages of a brûlé and on more than one brûlé. 


\section{Acknowledgements}

The survey was made possible thanks to Emma Brunet-Ruamps and Pierre Sourzat, the owner of the truffle ground and the Director of La Station de la Trufficulture de Cahors-Le Montat, respectively.

We would like to thank Alfredo Vizzini for helping in the identification and survey of the herbaceous plants, Stefano Ghignone for some bioinformatic help, Andrea Berruti for helping in the Mothur analysis, and Fabio Capone for helping in the experimental part. Fabio Capone's grant was funded by BIOBITs Project (Regione Piemonte). We also thank the three referees for helpful comments. The research was funded by Regione Piemonte as part of the "Tuber melanosporum soil card" project.

\section{References}

R. Borriello, E. Lumini, M. Girlanda, P. Bonfante, V. Bianciotto Effects of different management practices on arbuscular mycorrhizal fungal diversity in maize fields by a molecular approach Biology and Fertility of Soils, 48 (2012), pp. 911-922

A. Chao, M.C. Ma, M.C.K. Yang Stopping rules and estimation for recapture debugging with unequal failure rates Biometrika, 80 (1993), pp. 193-201

A. Chao, T.J. Shen, W.H. Hwang Application of Laplace's boundary-mode approximations to estimate species and shared species richness Australian and New Zealand Journal of Statistics, 48 (2006), pp. 117128

G.W. Douhan, C. Petersen, C.S. Bledsoe, D.M. Rizzo Contrasting root associated fungi of three common oakwoodland plant species based on molecular identification: host specificity or non-specific amplification? Mycorrhiza, 15 (2005), pp. 365-372

P. Frey-Klett, J. Garbaye, M. Tarkka The mycorrhiza helper bacteria revisited New Phytologist, 176 (2007), pp. 22-36

M. Giovannetti, D. Azzolini, A.S. Citernesi Anastomosis formation and nuclear and protoplasmic exchange in arbuscular mycorrhizal fungi Applied and Environmental Microbiology, 65 (1999), pp. 5571-5575

M. Gryndler, L. Cerná, P. Bukovská, H. Hršelová, J. Jansa Tuber aestivum association with non-host roots Mycorrhiza, 24 (2014), pp. 603-610 
M.M. Hart, R.J. Reader Taxonomic basis for variation in the colonization strategy of arbuscular mycorrhizal fungi New Phytologist, 153 (2002), pp. 335-344

T. Helgason, T.J. Daniell, R. Husband, A.H. Fitter, J.P.W. Young Ploughing up the wood-wide web? Nature, 394 (1998), p. 431

I. Hijri, Z. Sýkorová, F. Oehl, K. Ineichen, P. Mäder, A. Wiemken, D. Redecker Communities of arbuscular mycorrhizal fungi in arable soils are not necessarily low in diversity Molecular Ecology, 15 (2006), pp. 22772289

P. Kohout, R. Sudová, M. Janousková, M. Ctvrtlíková, M. Hejda, H. Pánková, R. Slavíková, K. Stajerová, M. Vosátk, Z. Sýkorová Comparison of commonly used primer sets for evaluating arbuscular mycorrhizal fungal communities: is there a universal solution? Soil Biology and Biochemistry, 68 (2014), pp. 482-493

M. Krüger, C. Krüger, C. Walker, H. Stockinger, A. Schüßler Phylogenetic reference data for systematics and phylotaxonomy of arbuscular mycorrhizal fungi from phylum to species-level New Phytologist, 193 (2012), pp. 970-984

J. Lee, S. Lee, J.P.W. Young Improved PCR primers for the detection and identification of arbuscular mycorrhizal fungi FEMS Microbiology Ecology, 65 (2008), pp. 339-349

E. Lumini, A. Orgiazzi, R. Borriello, P. Bonfante, V. Bianciotto Disclosing arbuscular mycorrhizal fungal biodiversity in soil hrough a land-use gradient using a pyrosequencing approach Environmental Microbiology, 12 (2010), pp. 2165-2179

H. Maherali, J.N. Klironomos Influence of phylogeny on fungal community assembly and ecosystem functioning Science, 316 (2007), pp. 1746-1748

A. Mello, C. Murat, P. Bonfante Truffles: much more than a prized and local fungal delicacy FEMS Microbiology Letters, 260 (2006), pp. 1-8 Minireview

A. Mello, C. Napoli, C. Murat, E. Morin, G. Marceddu, P. Bonfante ITS-1 versus ITS-2 pyrosequencing: a comparison of fungal populations in truffle-grounds Mycologia, 103 (2011), pp. 1184-1193 
A. Mello, G.C. Ding, Y.M. Piceno, C. Napoli, L.M. Tom, T.Z. DeSantis, G.L. Andersen, K. Smalla, P. Bonfante Truffle brulés have an impact on the diversity of soil bacterial communities PLOSOne, 8 (2013), p. e61945 http://dx.doi.org/10.1371/journal.pone.0061945

C. Napoli, A. Mello, A. Borra, A. Vizzini, P. Sourzat, P. Bonfante Tuber melanosporum, when dominant, affects fungal dynamics in truffle-grounds New Phytologist, 185 (2010), pp. 237-247

K.B. Nicholas, H.B. Nicholas, D.W. Deerfield GeneDoc: analysis and visualization of genetic variation Embnew News, 4 (1997), p. 14

F. Oehl, E. Sieverding, K. Ineichen, P. Mader, T. Boller, A. Wiemken Impact of land use intensity on the species diversity of arbuscular mycorrhizal fungi in agroecosystems of Central Europe Applied and Environmental Microbiology, 69 (2003), pp. 2816-2824

F. Oehl, E. Sieverding, J. Palenzuela, K. Ineichen, G. Alves da Silva Advances in Glomeromycota taxonomy and classification IMA Fungus, 2 (2011), pp. 191-199

M. Öpik, A. Vanatoa, E. Vanatoa, M. Moora, J. Davison, J.M. Kalwij, Ü. Reier, M. Zobel The online database MaarjAM reveals global and ecosystemic distribution patterns in arbuscular mycorrhizal fungi (Glomeromycota) New Phytologist, 188 (2010), pp. 223-241

M. Öpik, M. Zobel, J.J. Cantero, J. Davison, J.M. Facelli, I. Hiiesalu, et al. Global sampling of plant roots expands the described molecular diversity of arbuscular mycorrhizal fungi Mycorrhiza, 23 (2013), pp. 411430

G. Pacioni Effects of Tuber metabolites on the rhizospheric environment Mycological Research, 95 (1991), pp. $1355-1358$

I. Plattner, I.R. Hall Parasitism of non-host plants by the mycorrhizal fungus Tuber melanosporum Mycological Research, 99 (1995), pp. 1367-1370

P.D. Schloss, et al. Introducing mothur: open-source, platform-independent, community-supported software for describing and comparing microbial communities Applied and Environmental Microbiology, 75 (2009), pp. 7537-7541 
M.A. Selosse, A. Faccio, G. Scappaticci, P. Bonfante Chlorophyllous and achlorophyllous specimens of Epipactis microphylla (Neottiae, Orchidaceae) are associated with ectomycorrhizal Septomycetes, including truffles Microbiology Ecology, 47 (2004), pp. 416-426

C. Sigüenza, L. Corkidi, E.B. Allen Feedbacks of soil inoculum of mycorrhizal fungi altered by $\mathrm{N}$ deposition on the growth of a native shrub and an invasive annual grass Plant Soil, 286 (2006), pp. 153-165

L. Simon, M. Lalonde, T.D. Bruns Specific amplification of $18 \mathrm{~S}$ fungal ribosomal genes from vesiculararbuscular endomycorrhizal fungi colonising roots Applied and Environmental Microbiology, 58 (1992), pp. 291-295

S.E. Smith, D.J. Read Mycorrhizal Symbiosis (3rd edn.)Academic London (2008)

R. Splivallo, M. Novero, C.M. Bertea, S. Bossi, P. Bonfante Truffle volatiles inhibit growth and induce an oxidative burst in Arabidopsis thaliana New Phytologist, 175 (2007), pp. 417-424

R. Splivallo, S. Ottonello, A. Mello, P. Karlovsky Truffle volatiles: from chemical ecology to aroma biosynthesis New Phytologist, 189 (2011), pp. 688-699

E. Streiblová, H. Gryndlerová, M. Gryndler Truffle brûlé: an efficient fungal life strategy FEMS Microbiology Ecology, 80 (2012), pp. 1-8

J.D. Thompson, T.J. Gibson, F. Plewniak, F. Jeanmougin, D.G. Higgins The CLUSTAL_X windows interface: flexible strategies for multiple sequence alignment aided by quality analysis tools Nucleic Acids Research, 25 (1997), pp. 4876-4882

A. Trouvelot, J. Kough, V. Gianinazzi-Pearson Evaluation of VA infection levels in rootsystems. Research for estimation methods having a functional significance V. Gianinazzi-Pearson, S. Gianinazzi (Eds.), Physiological and Genetical Aspects of Mycorrhizae, INRA Press, France (1986), pp. 217-221

A. Turrini, M. Giovannetti Arbuscular mycorrhizal fungi in national parks, nature reserves and protected areas worldwide: a strategic perspective for their in situ conservation Mycorrhiza, 22 (2012), pp. 81-97 